\title{
Thinking Beyond Generations: On the Future of Revolution Theory ${ }^{1}$
}

\author{
forthcoming, 2021, Journal of Historical Sociology
}

\author{
Colin J. Beck \\ Pomona College \\ cbeck@pomona.edu \\ Daniel P. Ritter \\ Stockholm University \\ daniel.ritter@sociology.su.se \\ 4,878 words; 1 Figure
}

\begin{abstract}
A recent exchange between Allinson (2019) and Abrams (2019) on the current state of revolution theory rests on the assumption that the generational, backward-looking view of revolution studies is also a fruitful way of thinking of the field's present and future. We argue, in contrast, that while a generational approach has important benefits, it also contains shortcomings that may lead the future of revolution studies in less fruitful directions. We examine where an overreliance on generational thinking has led us, and provide an exploratory sketch of how we can begin to move beyond generational thinking and imagine a new future for the study of revolution.
\end{abstract}

${ }^{1}$ We gratefully acknowledge the helpful comments we received from George Lawson, Jack Goldstone, Eric Selbin, and Benjamin Abrams. 


\section{Introduction}

It is with great interest that we read the exchange between Jamie Allinson (2019) and Benjamin Abrams (2019) on the state of revolution theory in the social sciences, and not just because our works are among those that represent, for Allinson, a failed fifth generation or, for Abrams, a self-monitored fourth generation. We do not seek to quibble with their insights and critiques. Rather, we propose that their debate has taken place on false premises. Jack Goldstone's $(1982,2001)$ formulation of generations of revolution theory has been an invaluable orientating tool for virtually every student that has entered the field over the past four decades. However, it has also led to the establishment of an overly neat and consolidated perception of the field. Goldstone's historical-theoretical review of the literature has become reified as the actual history of the subfield in a way that at times limits our ability to assess what has been discovered about revolutions and, more crucially, prevents us from seeing where the path ahead lies by locking us into the idea that the future of revolution too will be constructed along generational lines. Hence, we believe that Goldstone's generational framework has been taken out of context and transformed beyond its original aim by subsequent generational reviews of the field. Rather than being a tool for understanding and consolidating past gains, it has become the only way authors believe they can structure the field's present and future.

By way of critique of the Allinson and Abrams exchange, we propose to take the field beyond generational thinking. We argue that a persistent focus on generations is misguided as debates in revolution research actually occur laterally among contemporaneous studies of revolution, rather than sequentially between reified paradigms. This is partially a consequence of mistaking touchstone texts for generations of scholarship (see for instance Ritter's (2015: 9-12) review of the literature, which Beck (2020) has thoroughly dismissed). As such, we have lost sight of our accumulated knowledge over the last one hundred years. In fact, the basic contours of what revolution scholars should study, how they should study it, and how it should be explained is largely settled. Consequently, it is time to imagine a new future for the study of revolution.

\section{The Limits of Generational Thinking}

While not the first article to seek to make sense of subfield (see for instance Stone 1966), no essay has had more impact on the way scholars think of the development of revolution theory than Goldstone's (1980) overview of the early to mid-20th century. Updated two decades later (Goldstone 2001), Goldstone proposes that the study of revolution has come in the form of generations, where a general understanding of what was to be explained was widely shared by scholars who had common methodological and theoretical approaches. Goldstone identifies an early-20th century first generation, which he terms "the natural-history school" (Goldstone 1982: 189), that focused on the sequential 
progression of the revolutionary process in classic cases of revolution, such as France in 1789. In response, a second generation of scholars sought to place revolutions in the field of collective political violence, focusing on more general theories that connect the individual, psychological causes of discontent with social unrest. Since Goldstone's initial formulation, this approach has become known as the generation of social and psychological strain theories. The third generation, termed "the structural-theory school" (Goldstone 1982: 189), moved the problem towards understanding why some revolutionary episodes succeed and others fail. This approach has become most associated with Theda Skocpol's (1979) state breakdown theory to the extent that the two are largely synonymous.

Most recently, theories of revolution for the past 25 years have been seen as belonging to a fourth generation that has an epistemology of conjunctural causation, dynamic eventful analyses, and an ever-expanding universe of factors under consideration (see Lawson 2019). It is here where Allinson (2019) and Abrams (2019) differ. For Allinson, the fourth generation represents a return of agency-centered explanations that was eclipsed by a short-lived "fifth generation" examination of unarmed revolutions and changes to political regimes. For Abrams, the current focus on revolutions like the Revolutions of 2011 is a continuity of fourth generation approaches, and thus a fifth generation is yet to develop.

One obvious problem with these accounts is that generational thinking has obscured the long-standing roots of different approaches and the remarkable re-occurrence of theoretical imagery across different scholarly eras (Beck 2020). We highlight a few examples. First, the natural history school never entirely died out, as is seen in Sohrabi's (1995) account of revolutionary eras. More recently, the turn towards theories that highlight the salience of how actors interact during the course of revolution (Ermakoff 2015; Kurzman 2004b) shares much of the epistemology of natural history and might be considered its $21^{\text {st }}$ century heir. Second, a focus on the state as the primary arena, and actor, for revolutionary claims predates Skocpol by over a century. Alexis de Tocqueville's (1856) account of the French Revolution is remarkably state-centered and can be considered the first modern work in the social science of revolution (see Goodwin 2001). Structural theorization also re-occurs across the so-called generations, whether in Merriman's (1938) comparative history, Johnson's (1966) modernization model, or Lawson's (2019) mechanistic account. Third, even strain theories of revolution have re-occurred, as grievances are a central point of some natural histories (Sorokin 1925) and a feature of some recent work (e.g., Beissinger 2013; Nepstad 2011; Snow and Moss 2014). And, finally, the generational account has obscured the contributions of Marxist theories of revolution that date from the $19^{\text {th }}$ century but live on in pieces into the $21^{\text {st }}$ (e.g., Boswell 2004; Foran 2005).

Goldstone's initial formulation was in equal parts exhaustive and crisp, thus inviting subsequent authors to adopt his framework rather than seek their own. As a result, it is uncommon to find reviews of the revolution literature that do not follow a generational 
typology. Because of this vast Goldstonian influence, the metaphor of generations has at times limited our view of the field's actual progression, and, importantly, how we collectively envision that development.

In our view, a complimentary way of approaching the field of revolution, which might remedy some of the unintentional shortcomings of the generational view, is to think of it as a series of recurrent debates. What should be the object of study: cases of successful transformation or cases of various forms of collective action? What should be the method of study: deep understanding of a particular case or general patterns in a universe of cases? What should be the core theoretical imagery: the distal causation of underlying conditions or the process of revolution itself? At any given point, there were always advocates for both sides of a question. But the metaphor of generations inaccurately suggests that each era of scholarship breaks with its predecessor rather than builds on it. For instance, the natural historians did not so much leave aside whiggish history as much as they put it to use in service of the emergent science of society. Strain theorists pioneered new models of collective behavior, synthesizing previous observations into general laws. And structuralists were arguing for or against Marxist theories of revolution as much as general models of collective violence. In short, it is perhaps more fitting to think of debates as occurring laterally — that is, within a "generation" — than thinking of them as occurring sequentially_ that is, across generations.

Another potentially unfortunate and inadvertent consequence of generational thinking is that it may promote the idea that past generations have been proven to be "incorrect." The consequence of this is that the baby—-specific insights—is thrown out with the generational bathwater, perhaps due to a scholarly fear that returning to past understandings indicate both a lack of knowledge of the field's history and, worse yet, an absence of theoretical vision. In other words, key insights from past generations may become damaged goods that one should preferably avoid engaging, other than in one's generational review of the literature or as straw humans to hack down. The result of such an approach is detrimental to our collective effort to understand revolutions, as theory construction often occurs from the synthesis of pre-existing ideas, insights, and concepts. This leads to our next point.

\section{The Problem of Canonization}

Generational thinking has also led to the canonization of some works and the forgetting of others. Each so-called generation has a book that is taken to be emblematic of an approach. As with any canon, this is constructed after the fact. For instance, the enduring popularity of Brinton (1938) is reflected in two recent titles: The Anatomy of Revolution Revisited (Stone 2013) and Anatomies of Revolution (Lawson 2019). This is somewhat ironic as it is, in fact, Edwards's (1927) The Natural History of Revolution that gave the school its name, to say 
nothing of the largely forgotten contributions of Sorokin (1925) and Merriman (1938). Similarly, a reliance on Gurr (1970) as a stand-in for strain theory in the revolution tradition has obscured the more erudite models of Smelser (1962) and Johnson (1966). And the dominance of Skocpol (1979) has led to the marginalization of other contemporaneous structural accounts, such as Paige (1975), and mistakenly made the third generation equivalent with state breakdown theory. Taking these works out of the larger conversations that were a part of their production has contributed to the reification of generational thinking.

What is unique about the last few decades of revolution theory is that they have lacked such a touchstone text. This is where we believe Allinson and Abrams got off on the wrong foot. They repeat the common rhetorical move to pin the "fourth generation" not to empirical work, but a literature review; most commonly Goldstone (2001), but also Foran (1993). That there is no recent work to point to as emblematic of recent theorization is taken to illustrate a subfield in disarray, and thus the fourth generation is either a completed failure (Allinson) or a work in progress (Abrams). But canonization is itself a social construction. The fact that the generations exist in the first place, we could argue, is that a few texts are seen to be similar to a canonical text published around the same time. The key here is are seen.

Take, for example, Chenoweth and Stephan's (2011) Why Civil Resistance Works: The Strategic Logic of Nonviolent Conflict. Were this to be canonized as emblematic of early $21^{\text {st }}$ century revolution studies, we would think that the central break with third generation structural theory was an agentic turn towards movement strategy. However, this would leave aside the numerous insights that the last thirty years have brought. For instance, the role of leaderships in revolutionary movements (Selbin 1993), the impact of culture and ideology (Bukovansky 2002), the turn from revolutionary change to reform (Lawson 2005), causation of international conditions (Beck 2011; Foran 2005; Lawson 2015; Ritter 2015), and so on.

Without a clear symbol of "fourth generation" thinking, it is easy to mistake the era as a failure or argue that it has already been replaced. The very lack of a canonical text is, in fact, an advantage for recent scholarship. Here, our take is a variant of Abrams's argument, as we believe the diversity of recent approaches is a welcome development. In order to break with generational thinking, we need to get away from the idea that certain texts are linked to certain ways of thinking about revolution. Rather than an elitist conceptualization of knowledge accumulation-book $\mathrm{X}$ is the best one that occurred at time $\mathrm{Y}$-we argue that each scholar should make their own determination of which studies to base their work on. The field will develop best if it is turned into an open playing field where each text and each insight is assessed on its own merits, rather than compared to touchstones. 


\section{Hidden Knowledge Accumulation}

A final consequence of generational thinking has been the rhetorical move, in literature reviews and theoretical frames, to suggest that a dramatic break with the old is required for something new to be learned. Allinson's (2019) critique is very much in this vein. When we take this rhetoric seriously it is easy to conclude that there are no consistent findings within the study of revolution (see Kurzman 2004a). But, in fact, there are. We do not seek to repeat a catalog of findings here as we have already done so elsewhere (see Beck 2017, 2020; Goldstone and Ritter 2018). Rather, we suggest here that the central questions of the field that animated $20^{\text {th }}$ century debate- what to study, how to study it, and how to theorize-mostly have been settled.

The first point of debate in the first half century of revolution theory was what the object of study should be. On the one hand, revolutions could be taken to be only the cases of political and social change that were world historically important (Brinton 1938; Edwards 1927; Huntington 1968; Skocpol 1979). On the other hand, revolution could be taken to be one form of contentious politics more broadly and placed alongside riots, social movements, terrorism, civil war, and so on (Gurr 1970; McAdam, Tarrow, and Tilly 2001; Smelser 1962; Tilly 1978). After nearly a century of the social scientific study of revolution, such diametrical poles seem absurd. No longer do scholars only study successful transformations of state and society. And no longer do scholars see revolution as on a continuum of the irrational exuberances of collective behavior. Rather, revolutions are seen as a distinct process of collective action, where success and failure are outcomes to be explained rather than criteria for inclusion or exclusion in a study (e.g., Foran 2005; Goldstone 1991; Ritter 2015; Tilly 1993). And avowed revolutionary movements do exist, but the various types of contention that can result in revolutionary challenges need to be explained (e.g., Beck 2015; Chenoweth and Stephan 2011; Goldstone and Ritter 2018). In short, the object of study is clear to contemporary scholars: attempted and successful shifts in, at the very least, regimes or political structures that occur through irregular mass mobilization.

The second debate that animated prior scholarship was the method of study. Should the scholar examine cases for particular historical knowledge (e.g., Kurzman 2004b; McAdam et al. 2001) or should they seek general laws of revolution (e.g., Gurr 1970; Huntington 1968)? The epistemological debate here obscures what is essentially a methodological dispute. On the one hand, some preferred historical case comparative modes of inquiry and others preferred cross-national statistical analysis. Modern revolution studies, for the most part, does not make this false choice. For instance, Goldstone (1991) and Gould (1995) have shown how careful historical analysis can be combined with innovative quantitative study to leverage the advantages of both approaches. Even among recent statistical studies (e.g., Chenoweth and Stephan 2011; Kadivar 2018), case comparison is a common compliment to the average effects within a population. This is not to say that all 
studies of revolution employ mixed methods, but rather that methodological approaches are not mutually exclusive. Debates over method are thus of a time that is passed. This, however, has not settled the larger epistemological question: what should theories of revolution focus on? This leads us to the third point of debate.

Finally, there can be disagreement over the core theoretical imagery of revolution studies. On one hand, should revolution be understood as resulting from broad causal conditions (e.g., Foran 2005; Goldstone 1991; Skocpol 1979) or seen as a dynamic process (e.g., Ermakoff 2015; Kurzman 2004b; McAdam et al. 2001)? In essence, this is an epistemological debate over the role of structure and agency in revolutions. This debate is not settled, and we should not expect one subfield to solve the structure-agency problematic. We suggest, however, that a feature of recent scholarship is to leverage both lines of thought. For instance, both Lawson (2019) and Ritter (2015) combine a backdrop of causal conditions with an account of how particular cases of revolution unfolded in the streets. Now it is possible to prefer structure, as does Ritter, or lean slightly more towards agency, as does Lawson, but it need not be to the exclusion of the other. With time, we may in fact see that the advantage of the so-called fourth generation (Abrams 2019) or failed fifth generation (Allinson 2019) was to sidestep theoretical disagreement in favor of empirical work. As with methodology, preference for particular causal imageries may just be an academic parlor game that has gotten in the way of knowledge accumulation (see Beck 2018).

Related to this final point, generational thinking constitutes a particular obstacle to the study of revolutions, due to the fact that theorization has long been perceived as central to the subfield. This has meant that reviews of the literature tend to obscure the distinction between empirical findings and theoretical contributions. Put differently, what we think we know about revolutions has historically been framed as pre-packaged theoretical solutions advanced by individual authors to revolution-related puzzles that "fit" with other such individual insights produced at a similar point in time, rather than empirical insights that can serve as inspiration to and be adapted by other scholars. By suggesting we have not achieved a substantial advance until some consensus on a new generation emerges, we risk losing sight of important, untheorized empirical insights that might quite plausibly give rise to future theoretical breakthroughs.

In sum, if we free ourselves of the metaphor of generations of revolution theory, then we are able to see not only the continuity of debates over the decades but their (mostly) successful resolutions. Contemporary revolution studies have a consensual object of study, a pluralistic methodology, and a potentially fruitful empirical core. This success, and we are comfortable calling the last century of the social science of revolution successful, should not be obscured by a rhetoric emphasizing the need to throw out the old and remake the field 
anew. If there is something to generational thinking, it is only that: calls to do away with prior scholarship seem to re-occur every 20 years or so.

\section{The Future of Revolution Theory}

Our point thus far has been that the metaphor of generations of revolution theory creates a false premise on which we debate progress or the lack thereof. We see previous work as caricatures rather than as products of a larger scholarly conversation. And we lose track of what has been settled and what remains to be explained. If we free ourselves from wondering what the fourth generation was or is, and what the fifth generation is or will be, we can begin to chart a more fruitful future for the study of revolution.

What any field needs, and what revolution theory currently requires, is novelty.

Rather than musty generational debates, we need creativity in theory, empirics, and resulting implications. In ideal-typical terms, there are two dimensions to any study of revolution. On the one hand, research can be theoretically-oriented-focused on developing new understandings - or empirically-oriented - focused on explaining substantive phenomena.

On the other hand, research can have universal implications for understanding revolution or more specific, particularistic claims about certain cases. Figure 1 presents these dimensions as a two-by-two table, highlighting four potential sources of novelty in the study of revolution with examples from the last two decades of research.

[Figure 1 about here]

First, there is novelty that results from theory-oriented research that has universal ambitions. Work here tends towards theoretical parsimony combined with the examination of well-known cases. For instance, Foran (2005) argues that recent Third World revolutions can be explained by the combination of five factors - dependent development, exclusionary regimes, a culture of opposition, economic downturns, and a world systemic opening. In another example, Lawson (2019) searches for recurrent mechanisms across executed and attempted cases of revolution ranging from the early modern world to the present. $\mathrm{He}$ concludes that there are eight processes that occur across revolutions-inter-social relations, loyalty or disloyalty of coercive forces, regime type, state stability, innovative oppositional strategy, factionalism among revolutionaries, continued contestation after the fall of a regime, and limited economic gains for the post-revolutionary state. Both of these works share the theoretical ambition to explain revolutions generally and the empirical incorporation of many cases. As such, they generate novel insight into the patterns of revolutions and their outcomes.

At the opposite pole is research that is empirically-oriented explanation of particular instances of revolution. Here the objective is the incorporation of new cases into the 
revolution literature, whether from current events or the successful recovering of past history. For instance, as the Arab Revolutions of 2011 spread, scholars took voluminous notice of the cases without necessarily making broad claims about the nature of revolution. For example, Ketchley (2017) examines Egypt in 2011 and afterwards using well-known tools of analysis to explain why and how protestors were able to oust Mubarak and unable to consolidate their gains. Novelty here comes from the success of affirming the membership of an event in the fold of revolution studies. The approach contributes to the field by expanding the case universe.

Third, other work seeks to explain new phenomenon rather than cases, with more universal import. A primary example of this approach is the civil resistance literature. For instance, Chenoweth and Stephan (2011) build on this approach to establish through statistical analysis and case examination that in the modern world unarmed strategies of resistance tend to have more success than armed ones. The goal for works of this type is to ask a new question — what are the causes and consequences of a relatively unrecognized aspect of revolution? - and offer answers that have implications beyond the cases at hand. Novelty thus comes from the examination of new dimensions of revolutions.

Finally, a fourth source of novelty is to create entirely new ways of understanding that focuses on particular instances of revolution. Here, the goal is usually not abstract parsimony but theoretical richness. Two recent examples of this approach are Selbin's (2010) consideration of the role of stories and narrative for revolutionary participants and Ermakoffs (2015) appraisal of how contingent decisions by individuals can radically change the direction of revolutionary events. Both consider the particulars of their examples, but provide new theoretical lenses for the field. Notably, they both also suggest different methodologies than are commonly used-oral history and decision-making trees. Novelty, here, thus comes from theoretical and methodological innovation.

Sometimes a field is moved forward by parsimony, sometimes by complexity. Sometimes it moves forward through events, sometimes through patterns. Thus, all of these approaches to revolution should be encouraged and embraced. Charles Tilly famously told his graduate students that there are three types of academic work: joining an ongoing conversation, changing the direction of a conversation, and starting a new conversation. The first is lower risk, and lower reward. Work on revolutions that explicitly places itself in generational debates is of this ilk. The second is medium-risk and medium-reward as it may or may not shift a debate. New abstract models of revolutions and examination of new cases are typical of this approach as they build upon the old rather than create anew. Finally, the third sort of conversation is high-risk and high-reward as it can spur new paradigms.

Research on new phenomena and new theoretical lenses are of this sort. On one hand, scholars of unarmed resistance have had great success at creating an entirely new conversation at the intersection of sociology, political science, and international relations. 
The flurry of work that Allinson sees as a fifth generation is proof of that. On the other hand, Selbin and Ermakoff have challenged us all to think of revolution differently.

The last century of revolution studies certainly has been a very long conversation. As such, it is unsurprising that we often repeat ourselves. But with a more accurate memory of what has been said by whom, to whom, and for which purpose, perhaps we can stop arguing over generations and resume debating ideas and phenomena. Only this way will we push our dialogue forward for another hundred years. 


\section{References}

Abrams, Benjamin. 2019. "A Fifth Generation of Revolutionary Theory Is Yet to Come." Journal of Historical Sociology 32(3):378-86.

Allinson, Jamie. 2019. “A Fifth Generation of Revolution Theory?” Journal of Historical Sociology 32(1):142-51.

Beck, Colin J. 2011. "The World-Cultural Origins of Revolutionary Waves Five Centuries of European Contention.” Social Science History 35(2):167-207.

Beck, Colin J. 2015. Radicals, Revolutionaries, and Terrorists. Cambridge, UK: Polity.

Beck, Colin J. 2017. "Revolutions: Robust Findings, Persistent Problems, and Promising Frontiers." Pp. 168-83 in States and Peoples in Conflict: Transformations of Conflict Studies, edited by M. Stohl, M. Lichbach, and P. Grabosky. New York, NY: Routledge.

Beck, Colin J. 2018. "The Structure of Comparison in the Study of Revolution." Sociological Theory 36(2):134-61.

Beck, Colin J. 2020. "Revolutions Against the State." Pp. 564-92 in The New Handbook of Political Sociology, edited by T. Janoski, C. de Leon, J. Misra, and I. Martin. New York, NY: Cambridge University Press.

Beissinger, Mark R. 2013. “The Semblance of Democratic Revolution: Coalitions in Ukraine's Orange Revolution.” American Political Science Review 107(03):574-592.

Boswell, Terry. 2004. "Hegemonic Decline and Revolution: When the World Is Up for Grabs." Pp. 149-62 in Globalization, Hegemony, \& Power: Anti-Systemic Movements and the Global System, edited by T. Reifer. New York, NY: Greenwood Press.

Brinton, Crane. 1938. The Anatomy of Revolution. New York, NY: Prentice-Hall.

Bukovansky, Mlada. 2010. Legitimacy and Power Politics: The American and French Revolutions in International Political Culture. Princeton, NJ: Princeton University Press.

Chenoweth, Erica, and Maria J. Stephan. 2011. Why Civil Resistance Works: The Strategic Logic of Nonviolent Conflict. New York, NY: Columbia University Press.

Edwards, Lyford Paterson. 1927. The Natural History of Revolution. Chicago, IL: University of Chicago Press.

Ermakoff, Ivan. 2015. "The Structure of Contingency." American Journal of Sociology 121(1):64-125.

Foran, John. 1993. "Theories of Revolution Revisited: Toward a Fourth Generation?” Sociological Theory 11(1):1-20.

Foran, John. 2005. Taking Power: On the Origins of Third World Revolutions. New York, NY: Cambridge University Press. 
Goldstone, Jack A. 1980. "Theories of Revolution: The Third Generation,” World Politics 32: 425-453

Goldstone, Jack A. 1982. "The Comparative and Historical Study of Revolutions." Annual Review of Sociology 8(1):187-207.

Goldstone, Jack A. 1991. Revolution and Rebellion in the Early Modern World. Berkeley, CA: University of California Press.

Goldstone, Jack A. 2001. “Toward a Fourth Generation of Revolutionary Theory.” Annual Review of Political Science 4(1):139-87.

Goldstone, Jack A., and Daniel P. Ritter. 2018. "Revolution and Social Movements." Pp. 682-97 in The Wiley Blackwell Companion to Social Movements. John Wiley \& Sons, Ltd.

Goodwin, Jeff. 2001. No Other Way Out: States and Revolutionary Movements, 1945-1991. New York, NY: Cambridge University Press.

Gould, Roger V. 1995. Insurgent Identities: Class, Community, and Protest in Paris from 1848 to the Commune. Chicago, IL: University Of Chicago Press.

Gurr, Ted Robert. 1970. Why Men Rebel. Princeton, NJ: Princeton University Press.

Huntington, Samuel P. 1968. Political Order in Changing Societies. New Haven, CT: Yale University Press.

Johnson, Chalmers. 1966. Revolutionary Change. New York, NY: Little, Brown and Company.

Kadivar, Mohammad Ali. 2018. "Mass Mobilization and the Durability of New Democracies." American Sociological Review 83(2):390-417.

Ketchley, Neil. 2017. Egypt in a Time of Revolution: Contentious Politics and the Arab Spring. Cambridge: Cambridge University Press.

Kurzman, Charles. 2004a. "Can Understanding Undermine Explanation? The Confused Experience of Revolution." Philosophy of the Social Sciences 34(3):328-51.

Kurzman, Charles. 2004b. The Unthinkable Revolution in Iran. Cambridge, MA: Harvard University Press.

Lawson, George. 2005. Negotiated Revolutions: The Czech Republic, South Africa and Chile. Farnham: Ashgate Publishing.

Lawson, George. 2015. "Revolutions and the international." Theory and Society, 44(4): 299-319.

Lawson, George. 2019. Anatomies of Revolution. Cambridge University Press.

McAdam, Doug, Sidney Tarrow, and Charles Tilly. 2001. Dynamics of Contention. New York, NY: Cambridge University Press. 
Merriman, Roger Bigelow. 1938. Six Contemporaneous Revolutions. New York, NY: Jackson, Son and Company.

Nepstad, Sharon Erickson. 2011. Nonviolent Revolutions: Civil Resistance in the Late 20th Century. New York: Oxford University Press.

Paige, Jeffery M. 1975. Agrarian Revolution. New York, NY: Free Press.

Ritter, Daniel. 2015. The Iron Cage of Liberalism: International Politics and Unarmed Revolutions in the Middle East and North Africa. Oxford: Oxford University Press.

Selbin, Eric. 1993. Modern Latin American Revolutions. Boulder, CO: Westview Press.

Selbin, Eric. 2010. Revolution, Rebellion, Resistance: The Power of Story. London: Zed Books.

Skocpol, Theda. 1979. States and Social Revolutions. New York, NY: Cambridge University Press.

Smelser, Neil J. 1962. Theory of Collective Behavior. New York, NY: Routledge \& Kegan Paul.

Snow, David A., and Dana M. Moss. 2014. "Protest on the Fly Toward a Theory of Spontaneity in the Dynamics of Protest and Social Movements." American Sociological Review 79(6):1122-43.

Sohrabi, Nader. 1995. "Historicizing Revolutions: Constitutional Revolutions in the Ottoman Empire, Iran, and Russia, 1905-1908.” The American Journal of Sociology 100(6):1383-1447.

Sorokin, Pitirim A. 1925. The Sociology of Revolution. Philadelphia, PA: J.B. Lippincott Company.

Stone, Bailey. 2013. The Anatomy of Revolution Revisited: A Comparative Analysis of England, France, and Russia. Cambridge University Press.

Stone, Lawrence. 1966. “Theories of Revolution.” World Politics 18(2):159-76.

Tilly, Charles. 1978. From Mobilization to Revolution. New York, NY: McGraw-Hill Publishing Company.

Tilly, Charles. 1993. European Revolutions, 1492-1992. London: Blackwell Publishers.

Tocqueville, Alexis de. 1856. The Old Regime and the Revolution. New York, NY: Harper \& Brothers. 
Figure 1. Four Types of Novelty in Recent Revolution Studies

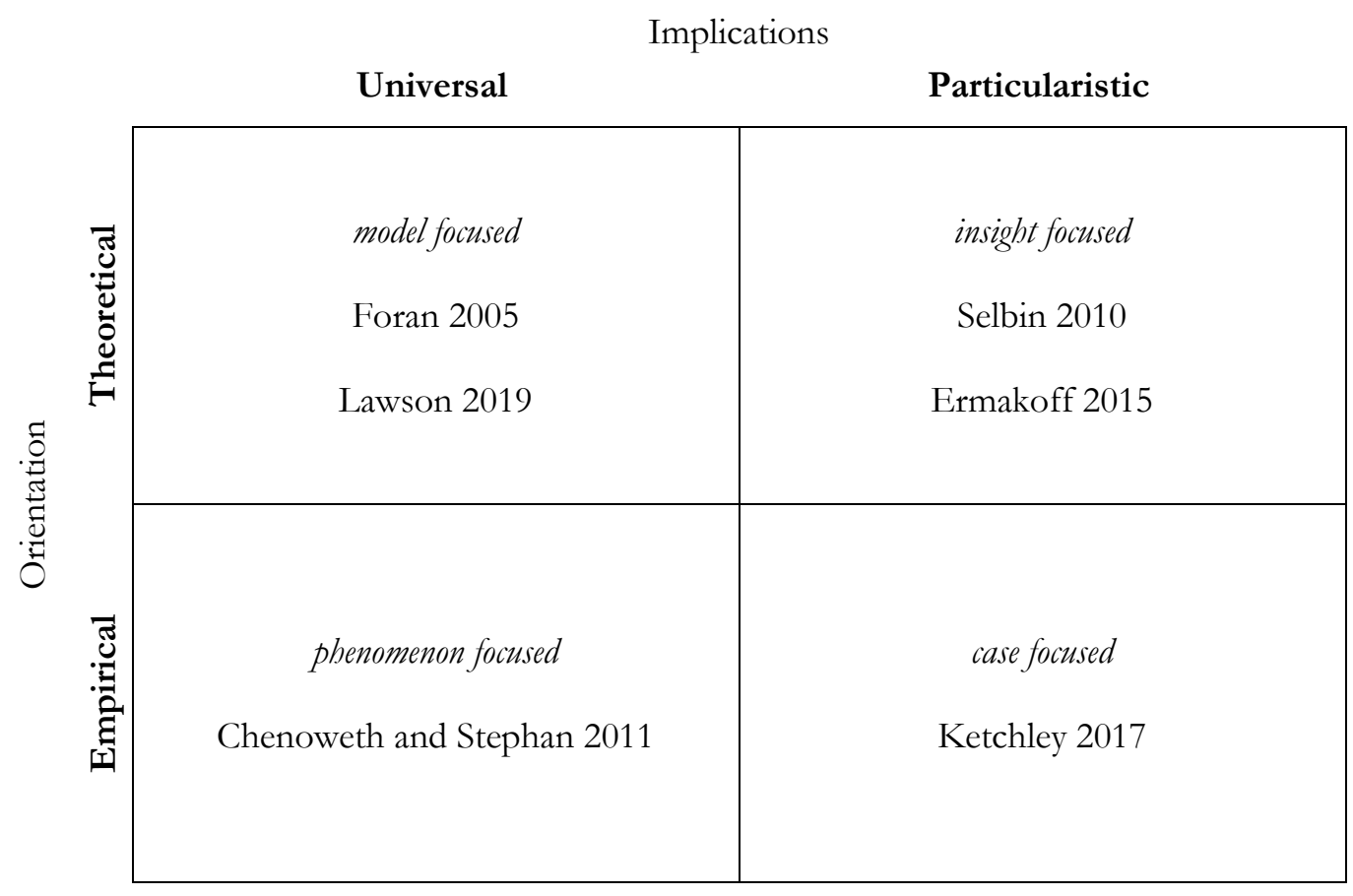

